\title{
Miguel Angel Asturias y la "Nueva Novela"
}

Se ha puesto de moda denigrar las novelas de la generación anterior porque, según piensan algunos, han dado una visión exterior de los personajes y de su mundo. Con sus preocupaciones de orden social, los hombres aparecen en ellas divididos en buenos y malos, sin tener en cuenta matices y contradicciones. Cuántas veces herros leído la palabra "maniqueismo" para definir ese tipo de literatura. Además, hoy día algunos abominan de aquel tipo de relato rectilíneo sometido a la cronología, de una expresión tan clara que el lector sigue sin mayor esfuerzo la hilación. Los que así opinan sobreponen a una concepción de la novcla otra que mañana o pasado parecerá tal vez tan artificial como la anterior. La "nueva novela" no deja de tener sus detractores. Ultimamente uno de los escritores de la Academia Goncourt ironizaba por la radio, diciendo de la "nueva novela" que ni era nueva ni novela. Nos contentaremos con apuntar la polémica sin entrar en ella.

En aquella novela hispanoamericana se trataba ante todo de cenunciar o protestar, o cuando menos de describir la sociedad. Lo urgente eta evidenciar hechos, escándalos. Y más claro el mensaje, mejor. En ciertos reparos que se le hace se puede ver también el reflejo del eterno conflicto entre las generaciones, con el consabido desdén de la última para con la anterior, como si en literatura, contradiciendo la copla famosa, "cualquier tiempo presente fuese mejor".

¿A qué viene esta salida a propósito de M. A. Asturias y la "nueva novela"? A lo que sigue; en este artista conviven dos generaciones, dos concepciones de la novela; $y$ en su obra se verifica una hermosa sintesis de las características más originales, más tradicionales y modernas de la novela hispanoamericana. Además, las novelas de M. A. Asturias, lo mismo que el Popol $V u b$ o las novelas de caballeria (reivindicadas por M. 
Vargas Llosa) enlazan curiosamente con lo que se suele llamar "nouveau roman", siendo, sin embargo, muy distintas de éste.

El ilustre guatemalteco declaró en Estrasburgo: "Que algún día la justicia llegue a nuestros países y empezaremos con las novelas de carácter psicológico, con el nouveau roman, que habrá también en América, pero mientras aquello no suceda, nosotros tenemos que seguir dentro de nuestra norma de una literatura comprometida con nuestros pueblos."1

Sin discrepar del todo en este punto, quisiera, sin embargo, proponer una interpretación algo distinta. Si M. A. Asturias aludió solamente al "roman nouveau" francés, puede ser que tenga razón; aunque, a no ser que se trate de una mera imitación, la novela hispanoamericana no será nunca $-\mathrm{y}$ tanto mejor - el "nouveau roman". Pero viene manifestándose desde hace años una nueva novela hispanoamericana relacionada con la norteamericana y la europea, y al mismo tiempo felizmente original, que tienc exponentes internacionalmente admirados, entre los que figura el mismo M. A. Asturias.

Esto no lo digo porque sí. Recordaré una declaración que me viene de perlas: "Yo creo que Asturias es uno de los grandes renovadores de la novela latinoamericana." Esta afirmación se publicó en Mundo Nuevo (No 1, p. 19) y la hizo uno de los más exitosos novelistas mexicanos de los últimos años, Carlos Fuentes.

Y ya que me refiero a Mundo Nuevo, sacaré de esta revista un párrafo significativo, en el que Emir Rodriguez Monegal, descubridor de los talentos más nuevos, dice: "El caso de Miguel Angel Asturias en la generación anterior de novelistas es bastante singular (...) Es un escritor al que le interesan mucho los problemas políticos y sociales $(\ldots)$ Sin embargo sus obras más creadoras revelan un novelista al que le importa mucho la invención de un lenguaje propio." (No 1, p. 10).

Sin dármelas de psicoanalista $y$ sin perderme en un comentario de texto, me llama la atención el juicio de este crítico, quien, a todas luces, hace de M. A. Asturias un "caso (...) singular" en la "generación anterior". Es decir que M. A. Asturias ha escrito novelas de protesta social -como los de su generación-; "sin embargo" - y en esta entrecomillada locución estriba toda la diferencia elogiosa subrayada por el crítico-- el novelista guatemalteco ha mostrado su inquietud por "un lenguaje propio". Casi huelga decir que la búsqueda de un lenguaje propio es una de las obsesiones más angustiadas de los novelistas actuales.

1 Hommage de l'Unityersité de Strasburg à Miguel Angel Asturias, Tilas VIII, 1968 , p. 24. 
Asi reconocen la novedad de M. A. Asturias dos representantes de los "nuevos" en la novela y la crítica. Valgan estos testimonios para nuestro tema.

Conviene ahora destacar el parecer del mismo novelista, y poner de manifiesto los elementos que hacen de su arte algo tradicional y nuevo a la par, algo personal y al mismo tiempo colectivo, algo original y también relacionado con las preocupaciones de otros escritores, sean hispanoamericanos o extranjeros.

Lo más descollante y perdurable de la novela hispanoamericana, según M. A. Asturias, es su carácter de protesta. "Bernal Díaz del Castillo, dijo en una conferencia, escribe para protestat y él mismo lo dice: Escribo esta historia para protestar, cansado del conquistar ya con mi espada vieja, ante el Rey, porque no se me ha hecho justicia." (Homnage..., p. 19). En la misma conferencia, el escritor menciona Factundo, Amalia, como obras de protesta. Nosotros podemos completar estas declaraciones con otra del mismo, publicada en la revista madrileña Insula (N? 197): "Nuestra novela surge, por así decirlo, de la protesta social y política contra una serie de situaciones que eran aproximadamente las mismas en los diversos países hispanoamericanos."

Por lo que acabamos de leer, el credo del novelista se puede cifrar en la fórmula: arte y realidad social. Basta recordar el contenido de $E l$ Señor Presidente, Hombres de maiz, Viento fuerte, Weekend en Gudtemala, Los ojos de los enterrados, para comprobar la fidelidad al principio establecido: la denuncia de todas las formas de explotación humana.

Esa realidad social es asimismo el telón de fondo, $y$ hasta en muchas páginas el tema principal, de La región más transparente, de Carlos Fuentes, sátira en la que desfilan el "ruletero", la prostituta, y sobre todo la gente de "medio pelo" y toda la fauna pintoresca de los aprovechadores de la Revolución, o de los inútiles, de los fracasados, en un libro con capítulos de estudio sociológico, en el que se plantea el problema del mestizaje cultural de México, con el torbellino enloquecedor final que representa bastante bien el carácter complejo y hasta contradictorio de la capital: conflicto o armonización anhelada entre pasado y presente, riqueza y pobreza, espíritu revolucionario y aburguesamiento.

$\mathrm{Y}$, ¿qué nos dice $\mathrm{M}$. Vargas Llosa de su novela La ciudad y los perros? Al referirse al Colegio Militar Leoncio Prado, comenta: "...entrar allí era como entrar al Perú, descubrir al Perú (...); fue, por ejemplo, descubrir a los indios, a la gente de la selva, a la gente de la sierra (...) el Leoncio Prado es una realidad bastante representativa del Perú." 
El mismo, a propósito de La casa verde, escribe en Mundo Nuevo (No 3, pp. 66-67): "También quiere ser, como La ciudad y los perros, la descripción de un aspecto de la realidad peruana pero en niveles diferentes. A un nivel diriamos objetivo, a un nivel subjetivo, a un nivel mítico incluso."

La realidad social trasluce también, con protesta o sin ella, con ironía o franco repudio, en muchas novelas actuales. Elijamos para muestras: de Juan Rulfo, Pedro Páramo (el caudillismo muerto), de García Márquez, Cien años de soledad (la sociedad colombiana), de Manuel Mejia Vallejo, Al pie de la ciudad (la villa miseria), etc.

Así, pues, en este sentido, las novelas de M. A. Asturias están en una corriente que no se ha agotado todavía.

En un artículo de Mundo Nuevo ( $N^{\circ}$ 5, nov. de 1966), Ernesto Sábato afirma: "La diferencia que hay entre la novela de hoy y la novela del pasado es que el acento en la novela de hoy está en lo metafísico y no en lo costumbrista, no en la pura narración." Esta observación de un novelista-ensayista es pertinente. Se refiere más bien, tal vez, a la novela de E. Sábato y algunos argentinos, que a toda la novela hispanoamericana en general; sin embargo, no cabe duda que el novelista de hoy no pinta sólo un cuadro sino que trata de interpretar conjuntamente lo que se vislumbra o no se ve dentro y más allá del lienzo, y hasta fuera del caballete.

Enfoquemos ahora otro elemento al que sólo hemos aludido de paso un poco antes. Este elemento transforma la realidad, la metamorfosea, o más bien le da un carácter distinto de la realidad convencional, o, si se prefiere, colectiva: es el lenguaje. En muchos casos, si no en todos, los novelistas buscaban en las palabras los símbolos más significativos de los objetos o ideas que pretendian presentar al lector. Pero con la irrupción de la poesía en la novela, ésta ha venido a ser un laboratorio de creación idiomática. Los ejercicios de estilo, los malabarismos verbales, los retruécanos y los juegos lexicológicos más caprichosos o estrafalarios, esmaltan cierto tipo de novela. Hay ejemplos típicos de ese que podríamos llamar vértigo lingüístico en Tres tristes tigres, de G. Cabrera Infante, o en Rayuela, de J. Cortázar.

Nunca se ha hablado tanto de lingüística como en los últimos años, y esta preocupación no ha dejado de despertar ecos en la novela. Hasta en esto se nota el impacto de las circunstancias en la literatura. Además, pasaron por ahí el surrealismo, y, hace poco, el letrismo. 
Pues bien: en los estudios dedicados a la obra de M. A. Asturias sesuele hacer hincapié en su formación literaria durante la era surrealista, para explicar cietta manera de utilizar el lenguaje. Hace falta comentar esa observación si no se quiere correr el riesgo de prescindir, en la elaboración de la obra del novelista, de algo que se me ocurre mucho más. importante que un mero surrealismo literario accidental. Por cierto, $\mathrm{M}$. A. Asturias, al analizar la elaboración de sus novelas, se refiere a una "primera versión (...) completamente automática". ${ }^{2}$

Pero no se atiene nuestro escritor a esta escritura prima. Agreguemos que ese su automatismo, de todos modos, actúa en muchos casos por la virtud de varias reminiscencias, según un proceso intimamente relacionado con cierto tipo de lenguaje tradicional de origen sagrado.

Tratemos de puntualizar esto.

A partir de sus Leyendas de Guatemala, el escritor se entrega a la embriaguez de las palabras, a la fruición de paladear vocablos y sílabas. $\mathrm{Y}$ el realismo de algunos temas no está reñido con ese placer. Recordemos la primera frase de El Señor Presidente: "Alumbra, lumbre de. alumbre, Luzbel de piedralumbre".

Leamos ahora lo que dice el novelista acerca del lenguaje, en varias: ocasiones: " (...) mi frase, mi texto es un poco barroco, está muy vestido. Pero se lo debo yo indudablemente un poco a la tradición maya. Los mayas tenían pavor al vacío y entonces, por ejemplo, en los grandes. monumentos ellos los llenaban de figuras y así nos pasa a los escritores con esa ascendencia: buscamos mucha palabra."

Ahí tenemos una explicación cultural, estética y psicológica. Eso en cuanto a la riqueza verbal. En otro lugar, M. A. Asturias dice: "En el Popol-Vub y los antiguos textos indigenas, las palabras no sólo poseen un valor ritual, sino que constituyen la sustancia misma del culto. Son el alimento de los dioses, que se nutren sólo de ellas." (Luis Harss, op. cit., p. 105). Y también: "En Hombres de maíz la palabra hablada tiene. un significado religioso. Los personajes de la obra nunca están solos, sino siempre rodeados por las grandes voces de la naturaleza, las voces de los ríos, de las montañas." (Id., p. 104).

A lo cual tenemos que agregar aún el siguiente parrafito, revelador de una preocupación permanente por el lenguaje: "Creo que mi lenguaje en Mulata de tal tiene una nueva dimensión. En Hombres de maíz está

- Miguel Angel Astarias o la tierra florida, en Luis Harss, Los muestros, Ed. Sudamericana, Buenos Aires, 1966, p. 105.

${ }^{3}$ Miguel Angel Asturias opina sobie la actual novela latinoamericana, Literarias, Buenos Aires, 8 de febrero de 1968. 
todavía sobrecargado de terminología religiosa y mítica. Mulata, en cambio, está escrita en el lenguaje popular, como una especie de picaresca verbal, con el ingenio y la fantasía que tiene la gente sencilla para hilar frases y jugar con las ideas." (Id., p. 123).

Ahora bien: no sé si hay menos terminología mítica en Mulata de tal que en Hombres de maiz, ya que -explica más adelante M. A. Asturias- "la Mulata es una variación del mito de la luna y el sol", y, en dicha novela, abundan los mitos. Pero lo cierto es que el novelista, desde sus primeras novelas, atribuye a las palabras un papel profundo, y hasta una fuerza oculta. El poeta chileno Vicente Huidobro tituló una novela, la única que salió de su pluma quizá: Sátiro, o el poder de las palabras. Es obvio que, en la época surrealista, se pretendía encontrar en las palabras un sentido propio, sobrenatural, motor de pensamiento, y hasta capaz de producir efectos materiales, to mismo que ciertas oraciones o frases cabalisticas sin sentido aparente, tienen el poder, creen algunos, de forzar la voluntad de los dioses, o despertar las energías naturales. Así es como los escritores vanguardistas volvían a las antiguas supersticiones, revividas en los pueblos primitivos; así fue como M. A. Asturias, al mismo tiempo que descubría en París el surrealismo, descubría también el Popol-Vub, y, sensible a las inquietudes modernas, reavivaba así el lenguaje de la biblia de los mayas. Hubo, pues, un encuentro: a ese surrealismo fruto del magín europeo fertilizado por el recuerdo de textos míticos, se parecía aquella surrealidad milenaria de la cosmogonia indígena y de las creencias en el poder de las palabras que provocan la 1luvia, los truenos o los terremotos. Acuérdense del "viento fuerte" desatado al final de la novela por las palabras misteriosas de un brujo. Viento de venganza y muerte que llega huracanado desde los tiempos más remotos y se lleva por delante al mundo moderno.

En la conferencia que dio en Estrasburgo, M. A. Asturias dice: " $(\ldots)$ podemos $(\ldots)$ afirmar que entre los indígenas existieron formas de relato muy parecidas a la novela"; y, más adelante: "Y en la actualidad tenemos la posibilidad de encontrar en la Biblioteca Vaticana estos textos que, tengo entendido, el Padre Garibay, de México, va a paleografiar muy pronto, y tendremos dentro de algunos años, indudablemente, ya los primeros textos de nuestra más auténtica literatura: Ia literatura escrita por los indígenas con caracteres latinos en sus lenguas tespectivas." (Hommage... op. cit., p. 17).

Es una lástima que no conozcamos estos textos. Probablemente tengan algo que ver con el Popol-Vub y las leyendas contadas por M. A. Asturias, y que a él mismo le contaron cuando era niño, por lo menos 
algunas, según dicen los biógrafos. Si es así, comprobamos una coincidencia entre el poder que dan a las palabras los escritores modernos y la fuerza que reconocian en ellas los poetas religiosos antiguos.

Además el lenguaje de M. A. Asturias ilustra, como en muchas novelas actuales, las relaciones entre lo racional y lo irracional, to real $y$ lo irreal; es decir, que no sirve para describir separadamente dos mundos distíntos, sino que, por su misma ambigüedad, se mezclan lo objetivo y lo subjetivo. Para medir con precisión la parte que pertenece a ambos mundos sería necesario ser guatemalteco, o por lo menos vivir en Guatemala, y tener la misma cultura que M. A. Asturias. Si no, uno corre el riesgo de incurrir en el mismo error de los extranjeros que en la poesía de Federico García Lorca, por ejemplo, no pueden distinguir lo tradicional de lo inventado, ni de lo estilizado a partir de giros o motivos populares. Esa misma ambigüedad es una riqueza.

$\mathrm{Y}$ esto nos lleva a considerat otro rasgo de la novelística de $\mathrm{M}$. A. Asturias, también enfocado en la perspectiva de la nueva novela: y es lo que llamó el escritor el "realismo mágico". Este realismo mágico existe en las interferencias verbales y alusivas. Así, por ejemplo, en El Papa Verde, la palabra emporios permite la relación emporialistas / imperialistas, retruécano que resulta ser de paso una fórmula alusiva a una realidad concreta. ${ }^{1}$

Por otra parte, nuestro novelista confunde voluntariamente la realidad y la ficción, cuando escribe en el epígrafe de Weerkend en Guatemala: "No ves las cosas que pasan?... Mejor llamarlas novelas." Es decir que si, como dijo alguien, "lo verdadero no es siempre verosímil", se podría también argüir que lo inverosímil también hace parte de la verdad. Lo que involucra un enfoque realista. Pero, si bien M. A. Asturias se interesa por la realidad exterior, por los hechos sociales que va denunciando, también lo apasiona el mecanismo del pensamiento, cuando éste corre por su cuenta, sin el control de la razón, sin la necesidad de un discurso lógico, suelto, dando lugar a otro tipo de realidad que se desarrolla dentro del yo de cada individuo y que resulta enigmática para quien es ajeno a ella. Esto es lo que pasa en el "nouveau roman", cuando el novelista, en vez de contar algo desde afuera, lo cuenta desde adentro, como si el protagonista, entregado al capricho de su memoria, se contentara con recordar episodios, emociones, de modo anacrónico, anárquico, descuidando cualquier hilación que permitiese al lector atar cabos, porque lo que se pretende es que el lector se convierta en el protagonista, o en el mismo autor de la novela. No llega a tanto M. A. Asturias, porque siempre -menos tal vez en Mulata de tal, hay en esta 
novela algo mágico de otra índole- se perfila la realidad colectivamente visible.

Este doble plano aparece, por ejemplo, en Los ojos de los enterrados: el tema realista es la preparación clandestina de una huelga que ha de derrumbar la Dictadura y la Bananera. Gracias a esa victoria "Ya podían cerrar los ojos los enterrados que esperaban el día de la justicia". Esa. frase aclaratoria del título ilustra la intrusión del universo mítico e irracional en la realidad. En esa novela se interfieren a menudo el mundo subjetivo y objetivo, de modo que los individuos viven con plenitud sus: sueños o pesadillas, y conjuntamente su existencia con los otros. En otros. momentos se portan como ajenos a sí mismos. Así, con un procedimiento que se parece mucho al que se emplea en el "nouveau roman", en Los ojos de los enterrados, M. A. Asturias hace dialogar a una muchacha. consigo misma, durante varias páginas: "Has llegado (se dice ella) $(\ldots)$ Retira el pañuelo de tus ojos. Tus lágrimas asoman como pollitos gordos, pero no corren." 4

En esa misma novela, decíamos, se interfieren a menudo lo teal y lor subjetivo. Así en este párrafo: " $(\ldots)$ también resonaban los pasos entre los libros, en la biblioteca, y en la bombilla de la luz eléctrica y en la garrafa de agua cristalina, y en el techo que se abría, se partía, le caía encima... Ella sintió..., no..., no era la boca de Cayetano Duende la que se abría, sino el techo, el techo que acababa de derrumbarse sobre su cabeza, golpeándola con estas palabras: -Camelias rojas!

El santo y seña de los conjurados, en boca de Cayetano Duende, que significaba: "Todo había vuelto al silencio, menos su corazón, el péndulo, su lápiz y Cayetano Duende que se había dejado caer en un sillón y mo-. lía bajo las suelas de sus botas, arenillas de alguno de esos caminos subterrâneos." (p. 160).

Con más facilidad aún, por supuesto, se produce esa interfcrencia en el sueño. En este caso, lo fantástico asombra menos al lector, ya que se trata de un estado que cada uno conoce, en el que sabemos que las cosas son normalmente anormales o extravagantes. Pcro advertiremos que $M$. A. Asturias no traza siempre la frontera entre el sueño y la vigilia. As: cuando Lino Lucero, en Viento fuerte, duerme abrazado a un tronco de banano, creyendo que es el cuerpo de una sirena.

Surge en este caso -y en otros muchos- una realidad subjetivaque, en Mulata de tal, se carga de una fantasía endiablada, enriquecida con frecuentes referencias a la cosmogonía indígena, modificada, recreada por la imaginación inagotable del Gran Lengua que es M. A. Astu-

- Ed. Losada, Buenos Aires, 1960, pp. 84-98. 
rias. Este tipo de novela mágica, burlesca, es un caso en la literatura actual, y posiblemente la más insólita de la lengua española.

En suma, las novelas de M. A. Asturias tienen la singularidad de pertenecer por algunos rasgos al "nouveau roman", y por otros tienen una originalidad propiamente hispanoamericana, como La casa verde, de Ma. rio Vargas Llosa o Cien años de soledad, de Gabriel García Márquez, con unos caracteres especialmente locales; y también esa genialidad peculiar de los grandes creadores.

Université de Paris

Paul Verdevoye 
